\title{
SOCIETY FOR THE STUDY OF FERTILITY
}

\section{ANNUAL CONFERENCE}

T HE annual conference of the Society for the Study of Fertility was held in the Meeting House of the Zoological Society of London during July 22-23, when the opportunity was also taken to celebrate the fifth anniversary of the Society's existence. The proceedings opened with a paper by R. Irving-Bell on the routine clinical examinations carried out at the Male Subfertility Clinic at Bristol, followed by a group of three papers from the Department of Anatomy, Liverpool, by Prof. R. G. Harrison and his colleagues, on some fundamental aspects of the structure and function of the rat testis and the male accessory organs. In the first paper, concerned with the influence of freezing temperatures on the rat testis, Prof. Harrison and Miss Jean Macdonald elaborated in detail their thesis that the adverse effects of low temperatures on spermatogenesis are due directly to ischæmia. Next, E. W. Macmillan gave an account of his experiments on the anatomical factors in the male which determine the normal rate of disposal and dissolution of epididymal spermatozoa, and which predispose to the formation of spermatocoele. E. J. Clegg described the response of rat accessory glands to the interruption of arterial blood supply. His finding that, when deprived of the normal blood supply, the coagulating glands cease to secrete fructose is a good indication that the blood-flow in the accessory reproductive organs is of decisive significance for composition of the seminal plasma.

Dr. Cecilia Lutwak-Mann (Cambridge) spoke next on the physiology and biochemistry of the nearimplantation stages of pregnancy in the rabbit. She has found that very little glucose is present in the young unattached blastocyst (six days after fertilization), but that the content of this sugar begins to increase markedly as implantation progresses. This is in contrast to the content of bicarbonate ions, which in the unimplanted blastocyst are almost three times more concentrated than in the maternal blood but which decrease to maternal serum-level after the implantation. The remarkably high content of bicarbonate in the free-lying blastocyst coincides with the appearance in the mucosa of the pregnant uterus of carbonic anhydrase, the zinc-protein enzyme which is well known to be concerned with bicarbonate metabolism in the animal body. From Dr. LutwakMann's experiments concerning the passage of a variety of substances from the maternal blood stream into the blastocyst, it appears that, so long as the blastocyst remains free in the uterus, it is largely independent of major changes in the maternal blood composition. Once implantation is completed, several substances, including certain drugs, are capable of passing freely from the maternal blood into the blastocyst cavity.

This paper was followed by a group of three reports, all of them concerned with different clinical aspects of human infertility: D. M. Shotton (Birmingham) spoke on the obstetric management of infertile women, M. C. N. Jackson (Exeter) presented her records on the follow-up of infertility cases, extending over many years of observation, and Dr. $J$. Loewenstein (London) described in detail the use of mechanotherapy in subfertile men.

The session on the next day opened with a paper by Dr. E. J. Farris (Philadelphia) on the value of ovulation timing in the sterile couple, followed by two other guest-speakers from abroad: Dr. G. E. Seegar Jones (Baltimore), who discussed the relationship between adrenal hyperplasia and fertility, and Dr. Raoul Palmer (Paris), describing the use of coeliscopy in the diagnosis of reproductive disorders in women. The remaining papers centred largely on the problem of male sterility and sperm physiology and biochemistry. Dr. G. I. M. Swyer (London) commented eritically on the value of testicular biopsy as a clinical procedure. Dr. A. S. Parkes and Dr. P. Spensley, from the National Institute for Medical Research, Mill Hill, reported on their experiments with 'Rehibin', a condensation product of gentisic acid, and on certain other new macromolecular polyacids in relation to their action on hyaluronidase and the fertilizing capacity of rabbit spermatozoa. An interesting fact brought to light by these researches was that, in spite of the marked inhibitory effect on sperm-hyaluronidase which coincided with a decrease in fertilizing capacity, 'Rehibin' and similar polyhydroxybenzoic acid condensation products are not necessarily spermicidal agents-for example, they do not deprive the spermatozoa of their motility and metabolic activity.

Metabolic processes in spermatozoa and their relation to the so-called dilution effect were dealt with by Dr. M. W. H. Bishop (Cambridge), who reported also on the use of a new glycine-containing artificial medium in the practice of semen preserva. tion. He was followed by Dr. T. Mann (Cambridge), who spoke on the biochemical mechanisms underlying the action of spermicidal agents, and on his recent investigations which make it possible to distinguish clearly three groups of spermicidal substances : enzymic inhibitors, which act directly upon certain intermediary reactions in sperm respiration and fructolysis ; sulphydryl-binding substances which combine with the vital thio-groups in spermatozoa; and surface-active substances which owe their spermicidal property to a detergent action on lipoprotein and other protein-constituents of the spermcell.

As in previous years, the papers presented at the Conference will be published by W. Heffer and Sons, Ltd., Cambridge, as a separate volume (No. 6) of the Proceedings of the Society for the Study of Fertility.

\section{METEOROLOGY AND SCOTTISH AGRICULTURE}

TWO symposia were held by the Royal Meteorological Society as part of its summer meeting during July 15-17 in the Natural Philosophy Depart. ment of the University of Edinburgh. The first was on "The Upper Atmosphere" (see Nature, August 21, p. 334), and the second, which was held on July 17, was devoted to "Meteorology and Scottish Agriculture". The first speaker at this latter symposium was Dr. John Grainger (West of Scotland Agricultural College, Auchincruive), who suggested, by graded examples, that studies on relationships between climate and crop diseases should consider effects on the host plant, in addition to those on the parasite. 
The attainment of a soil temperature of $45^{\circ} \mathrm{F}$. $\left(7 \cdot 2^{\circ}\right.$ C. $)$, for example, imposes an initial limit to the activity of larvæ of the potato root eolworm, with no such limit to growth in the early Epicure potatohost. This has important economic and pathological repercussions, and the growth of such early crops provides, moreover, the only cultural possibility of obtaining even moderate yields on infested land. Low incidence of club root disease of swedes is associated with a relatively high soil temperature in July, relatively high amounts of bright sunshine in June, July and September, relatively low rainfall in September, and relatively high rainfall in October. The effect of bright sunshine on disease can only arise through its effect on the host. Practical measures for the grower would be to control soil moisture in September and October.

A second paper by Dr. Grainger, in which he had collaborated with J. L. Sneddon, E. de C. Chisholm and A. Hastie (Auchincruive), reported that higher yields of barley grain are related to lower maximum air temperature and higher rainfall in June. Tho production of bean grain is stimulated by higher average maximum air temperature in May, lower bright sunshine in June, and higher rainfall in July. Yields of oat grain are higher with lower average air temperature in July, and wheat grain with lower average air temperature in April and higher rainfall in July. Winter varieties of wheat give higher yields of grain when, in addition to these correlations with climate in April and July, there is a lower amount of bright sunshine in March. The practical value of the results lies in the precision they bring in sug. gesting that conservation of soil moisture is most necessary in particular months for each crop in a given area.

Dr. F. L. Waterhouse (University College, Dundee; University of St. Andrews) gave detailed assessments of seasonal and diurnal differences in climate within grass crops, with the view of their suitability for the development and successful existence of insects. The differences are mainly related to the height, density and mode of growth of the crop and also to the angle of the sun's rays. A matted basal layer of dead grass in wild grassland, or the co-existence of a clover crop in hay and silage fields, maintains a cool humid atmosphere next to the ground. This is favourable to insects when more arid conditions exist at higher levels, where wind speed is the most significant factor. These varying conditions can make available to an insect a considerable range of body temperatures and states of water-loss during periods of insolation. The presence of broad-leaved weeds can interfere with the relatively uniform habitat presented by pure grassland.

A preliminary report on continuous records of profile soil temperatures within an afforested area was given by Dr. J. R. H. Coutts (Soil Science Department, University of Aberdeen), who said that mean annual temperatures were found to be practically the same throughout the soil profile, but that inversions of the profile occurred in April and August. Future results from this study should yield information of considerable importance. Mr. J. M. Caborn (Forestry Department, University of Edinburgh) reviewed work on the effect of shelter belts on the climate of the areas influenced by them. $\mathrm{He}$ laid stress upon the density of the shelter. A completely dense belt, for example, is 80 per cent ineffective at 10 heights away in the lee, whereas a less-dense belt is effective 15 heights away, and a density of 50 per cent has been found to be the most effective. In detail the temperature in the lee of a shelter belt is often $1^{\circ} \mathrm{F}$. higher than in the open, during the day; relative humidity is about 3 per cent less in the lee, and soil moisture is about 1 per cent higher in this area. Crop yields have also been found to be higher in the lee of shelter belts.

Mr. F. H. D. Green (Nature Conservancy) considered the importance of climate and climatic studies on the ecological work of the Conservancy. One important conclusion is that the climate and conditions in mountain-top valleys should not be considered on a basis of their floor altitude, but as part of the mountain top itself. An indirect effect of summer rainfall on the response to phosphatic fertilizers was mentioned by Dr. A. M. Smith and Dr. K. Simpson (East of Scotland College of Agriculture, Edinburgh). It is fairly common knowledge that response to phosphatic fertilizers tends to be small in a dry season and high in a wet one. It was found, however, that the percentage recovery of phosphorus is more closely related to soil $p \mathrm{H}$ than to summer rainfall. The correlation between phosphate recovery and soil $p \mathrm{H}$ is, nevertheless, much more significant when the effects of summer rainfall are eliminated.

The symposium served a most useful purpose. Biologists and meteorologists have remained separate for too long, and it is to be hoped that this conscious joining of their forces may be followed by further similar meetings.

\section{ROYAL GREENWICH OBSERVATORY}

\section{ANNUAL REPORT FOR 1953-54}

$\mathrm{T}$

HE annual report of the Astronomer Royal for the period May 1, 1953-April 30, 1954 deals as usual with three separate sections of the Royal Greenwich Observatory in Greenwich, Abinger and Herstmonceux*. The Greenwich Octagon Room, which was formally opened on May 8, 1952 (referred to in last year's report), is accessible to the public, and Halley's transit and Bradley's zenith sector are displayed in the room, as well as copies of various old prints of the Observatory. A considerable amount of work has been done to the New Building, and the hot-air furnaces have been overhauled; repair and maintenance work has been carried out in the old buildings, and the boundary fences have been repaired and strengthened. A new boiler has been installed for heating the Record Rooms and Time Department Office.

The Yapp 36-in. reflector has been used with the single-prism spectrograph in continuation of observations of the standard stars of the Yerkes Atlas, and 86 spectra of 74 stars have been secured. During October 30-April 26, while the 21-ft. eclipse telescope was under test, the instrument was out of use. In last year's report reference was made to the proposal to televise Jupiter and its satellites, and on January 13 the scheme was carried out with great success; unfortunately, the next night, on which a full-scale programme was scheduled, was cloudy, and a 'standby programme' had to be substituted.

* Report of the Astronomer Royal to the Board of Visitors of the Royal Greenwich Observatory, Read at the Annual Visitation of the Royal Observatory, June 12, 1954. Pp. 30. (Herstmonceux : Royal Greenwich Observatory, 1954.) 